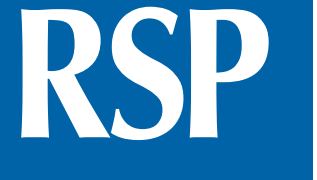

http://www.rsp.fsp.usp.br/
Revista de Saúde Pública

\title{
Brazilian cohorts with potential for life-course studies: a scoping review
}

\author{
Waleska Regina Machado Araujo' (iD, Iná S. Santos" (iD, Naercio Aquino Menezes Filho"I (iD, \\ Maria Thereza Costa Coelho de Souza ${ }^{\text {Iv }}$ iD, Antonio Jose Ledo Alves da Cunhav ${ }^{\text {iD, }}$ \\ Alicia Matijasevich ${ }^{\mathrm{v}}$ iD \\ ' Universidade de São Paulo. Faculdade de Medicina. Programa de Pós-Graduação em Saúde Coletiva. São \\ Paulo, SP, Brasil \\ " Pontifícia Universidade Católica do Rio Grande do Sul. Programa de Pós-Graduação em Pediatria e Saúde da \\ Criança. Porto Alegre, RS, Brasil \\ II' Universidade de São Paulo. Faculdade de Economia e Administração. Departamento de Economia. São Paulo, \\ SP, Brasil \\ Iv Universidade de São Paulo. Instituto de Psicologia. Departamento de Psicologia da aprendizagem, do \\ desenvolvimento e da personalidade. São Paulo, SP, Brasil \\ $\checkmark$ Universidade Federal do Rio de Janeiro. Faculdade de Medicina. Departamento de Pediatria. Rio de Janeiro \\ RJ, Brasil \\ v' Universidade de São Paulo. Faculdade de Medicina. Departamento de Medicina Preventiva. São Paulo, SP, Brasil
}

Correspondence:

Waleska Regina Machado Araujo

Av. Dr Arnaldo, 455, $2^{\circ}$ andar

01246-903 São Paulo, SP, Brasil

E-mail:waleskaregina@usp.br

Received: Jun 13, 2019

Approved: Aug 19, 2019

How to cite: Araujo WRM Santos IS, Filho NAM, Souza MTCC, Cunha AJLA, A Matijasevich. Brazilian cohorts with potential for life-course studies: a scoping review Rev Saude Publica. 2020;54:48.

Copyright: This is an open-access article distributed under the terms of the Creative Commons Attribution License, which permits unrestricted use, distribution, and reproduction in any medium, provided that the original author and source are credited.

\section{ABSTRACT}

OBJECTIVE: To identify the Brazilian cohorts that started either in the prenatal period or at birth, to describe their characteristics and the explored variables, and to map the cohorts with potential for studies on early determinants on health and the risk of falling ill on later stages of the life cycle.

METHODS: A scoping review was carried out. The articles were searched in the electronic databases PubMed and Virtual Health Library (VHL). The descriptors used were [((c"Child" OR "Child, Preschool" OR “Infant" OR “Infant, Newborn") AND (Cohort Studies" OR “Longitudinal Studies")) AND "Brazil")]. The inclusion criteria were Brazilian cohorts that started the baseline in the prenatal period or at birth and with at least two follow-ups with the participants. In order to meet the concept of LCE, we excluded those cohorts whose follow-ups were restricted to the first year of life, as well as those that did not address biological, behavioral and psychosocial aspects, and cohorts with data collection of a single stage of the life cycle.

RESULTS: The search step identified 5,010 articles. Eighteen cohorts were selected for descriptive synthesis. The median number of baseline participants was 2,000 individuals and the median age at the last follow-up was 9 years. Sample loss at the last follow-up ranged from 9.2 to $87.5 \%$. Most cohorts monitored two phases of the life cycle (the perinatal period and childhood). The Southern region had the highest number of cohorts. The main variables collected were sociodemographic and environmental aspects of the family, morbidity aspects, nutritional practices and lifestyle.

CONCLUSIONS: We recommend the continuity of these cohorts, the approach to different social contexts and the performance of follow-ups with participants in different phases of the life cycle for the strengthening and expansion of life course epidemiology analyses in Brazil.

KEYWORDS: Cohort studies. Child development. Health development. Analytical Epidemiology. Bibliometrics. Systematic Review. 


\section{INTRODUCTION}

Life course epidemiology (LCE) is a field that compromises the studies of biological, behavioral and psychosocial processes that occur throughout the life of individuals. It links the health conditions and the risk of illness of an adult to physical or psychosocial exposures that might have happened during pregnancy, infancy or adolescence, in the earlier stages of life or through generations ${ }^{1}$. Its purpose is to build and test theoretical models that might postulate paths that link exposures at different stages of the life course to later health outcomes ${ }^{2}$. These models explore the time and interactions of biological and psychosocial exposures to identify risks and protection processes throughout the life course $\mathrm{e}^{3,4}$.

As such, cohort studies are a valuable tool for LCE, as they follow their participants from exposure to the occurrence of outcomes of interest ${ }^{5}$. These studies are generally conducted to assess the natural history of diseases, estimate disease frequency measures (incidence), identification of risk factors for health problems, prognosis and survival analysis ${ }^{6,7}$. Cohorts that collect information at different stages of their participants' lives and with medium and long-term outcomes are excellent for testing explanatory models of $\mathrm{LCE}^{8,9}$, and it is possible to explore risk accumulation models and critical periods, in addition to investigating the mediating and modifying factors of the association between exposures and outcomes in study ${ }^{2,3}$.

Cohorts that start in the prenatal period or at birth offer a unique opportunity to assess the influence of early exposures on health throughout life ${ }^{4}$. They are mainly concentrated in high-income countries and differ from cohorts conducted in middle and low income countries by the greater number of follow-ups, follow-up of participants for longer periods and greater sophistication of the measures performed ${ }^{10}$. These cohorts, in middle- and low-income countries, offer valuable contributions due to the diversity of exposures and the different structures for disease determination ${ }^{11}$. In countries such as Brazil, with cultural diversity and regional inequality, they can offer contributions as valuable as cohorts from high-income countries. However, the research gaps of these studies in the country are not mapped, and a synthesis of information with the characteristics and outcomes studied by the main cohorts of this type is important in order to advance the studies of life course epidemiology throughout the country.

This study aims to describe the cohort studies initiated in the prenatal period or at birth conducted in Brazil, with the potential to study the early determinants of health and disease and the risk of falling ill in later stages of the life cycle. Through a scoping review, it was possible to describe the main methodological characteristics of these cohorts, as well as the variables studied, the location in the country and the needs related to epidemiological research of the life cycle in Brazil.

\section{METHOD}

We conducted a scoping review to identify and map the available evidence on Brazilian cohorts with potential for life course epidemiology studies. This review is conducted to summarize and disseminate the research results and recognize research gaps in the available literature ${ }^{12}$. We followed the following steps: identification of the research question ("What are the characteristics of the Brazilian cohorts started at birth and in the prenatal period with the potential to study the early determinants of health and disease and the risk of falling ill in later stages of the life cycle?"), identification of relevant articles, selection of studies, data mapping and compilation, summary and reporting of results. The articles were searched in the electronic databases PubMed and Virtual Health Library (VHL). The descriptors were selected at the Medical Subject Headings (MeSH) with the following combination: [(((Child” OR “Child, Preschool” OR “Infant” OR “Infant, Newborn”) AND (Cohort Studies” OR "Longitudinal Studies")) AND "Brazil”)]. The search strategy was adapted for each database. All articles published as of June 16, 2018 were considered in the review. 
The review included cohort studies conducted in Brazil that started the baseline of the study in the prenatal period or at birth and with at least two follow-ups with the participants. The studies excluded were those that described only the baseline and not the follow-ups performed. In order to meet the concept of LCE, we excluded those cohorts whose follow-ups were restricted to the first year of life, as well as those that did not address biological, behavioral and psychosocial aspects, and cohorts with data collection of a single stage of the life cycle. We considered as stages of the life cycle the perinatal period (between the 22nd week of gestation and six days of life), childhood (between the first week of life and six years of age), school age (between 6 and 12 years), adolescence (between 12 and 18 years) and adulthood (18 years or more) ${ }^{13}$. Two reviewers selected the titles and abstracts of the articles and read the full text of the eligible articles. Given that the scoping review aimed to map the evidence on a relevant topic, an evaluation of the quality of the evidence included in the review was not necessary ${ }^{12}$. Finally, from the interpretation of the results of this review, we presented recommendations to advance the studies of life course epidemiology in Brazil.

The following information was extracted from the selected studies: geographic location of the cohort (city, state, region); year of beginning of the cohort (baseline); type of cohort according to the age of baseline participants, divided into birth (recruitment of participants started at birth) and prenatal (recruitment initiated during pregnancy); type of cohort regarding the time of occurrence of exposure and outcome and the beginning of the study, divided into prospective (exposure data were collected at the beginning of the study and the outcome has not yet occurred), retrospective (exposure and outcome were defined based on the data that occurred before the beginning of the study, both in the past) and ambispective (exposure data were collected in the past and the outcome has not yet occurred); type of data used in the cohort, divided into primary (data collected for the first time, to meet the needs of the current cohort) and secondary (information obtained from previously collected data, which was not collected at the time of the research); reference base of the sample, divided into hospital-based (individuals of a hospital or health center) and populationbased (representative or convenience); number of participants in the baseline; number of participants in the last follow-up; average age of the participants in the last follow-up; total number of follow-ups with participants; mean age of participants in each follow-up; information collected at each stage of the life cycle.

These data were complemented with information extracted from publications from the list of references of selected articles, as well as from electronic pages of cohort studies, from contacting via e-mail researchers of these studies and consultations with databases of dissertations and theses. Finally, a descriptive analysis of the main characteristics of the cohorts included in the review was performed.

\section{RESULTS}

\section{Search Results and Article Selection}

The search stage identified 5,010 articles in the databases, excluding 1,678 duplicated ones. After reading the titles and abstracts, 2,904 articles were excluded because they did not meet the eligibility criteria. After reading the full text, 428 articles from 79 cohort studies conducted in Brazil initiated in the prenatal period or at birth with at least two follow-ups with the participants were identified. Of these 79 cohorts, 41 with follow-ups only during the first year of life and five that did not address biological, behavioral and psychosocial aspects were excluded. Due to the interest in analyzing cohorts that explored effects of exposures that occurred in the perinatal period, childhood, adolescence and in later stages of the life cycle, fifteen cohorts with data collection of a single stage of the life cycle were excluded. At the end, 18 cohorts were selected ( $n=345$ articles). The flowchart of the review steps is illustrated in Figure 1. 


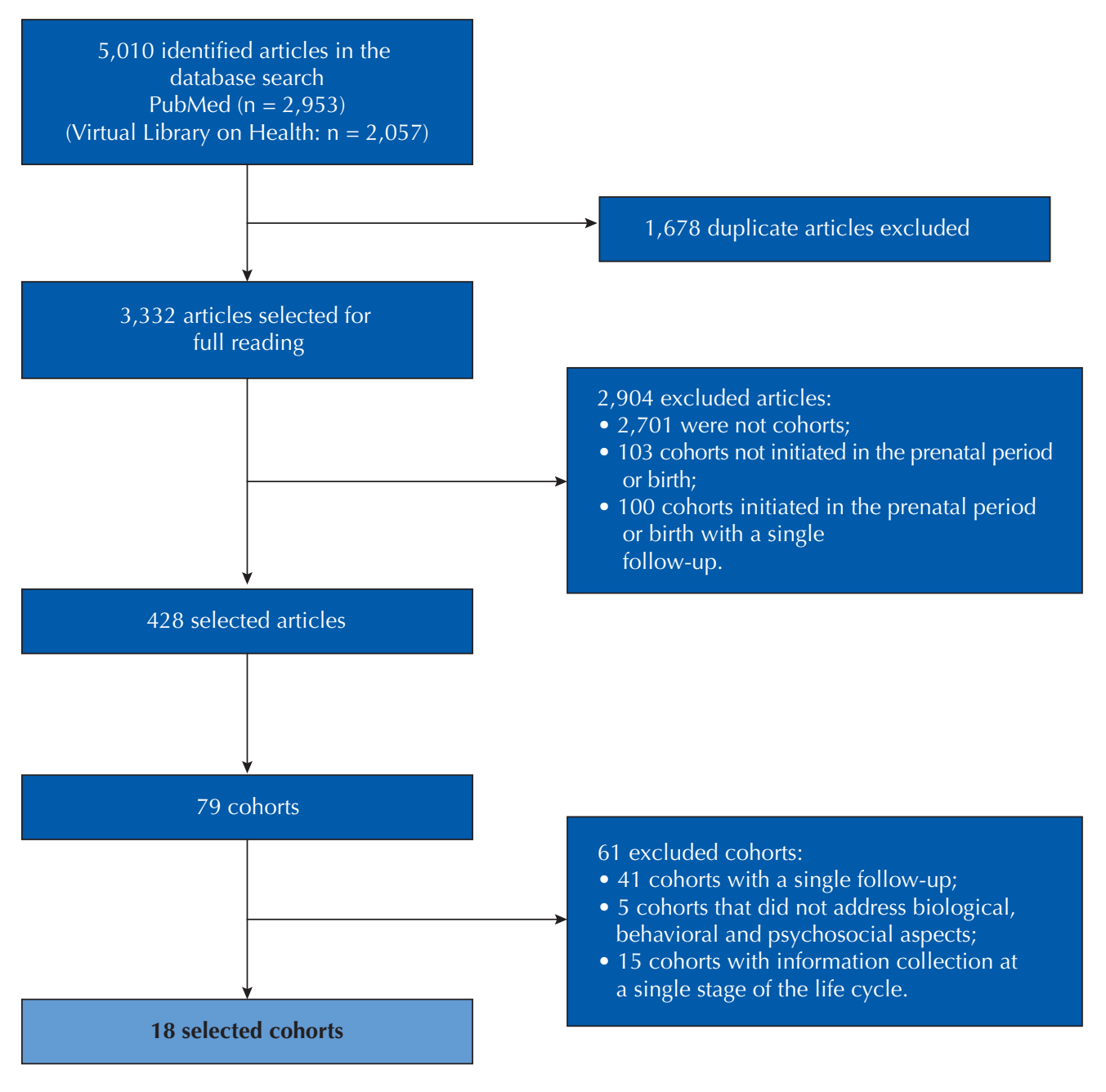

Figure 1. Flowchart of the search stage of the article selection in the systematic review.

\section{Description of Selected Cohorts}

Of the 18 cohorts identified ${ }^{14-31}, 15$ started at birth $^{14-22,24-29}$ and three, at the prenatal period ${ }^{23,30,31}$. All cohorts were prospective and collected primary data. Ten cohorts ${ }^{15,18,20-22,24-26,29,31}$ had a representative sample of the baseline reference population, seven cohorts ${ }^{14,16,17,19,27,28,30}$ used a convenience sample, and a single cohort was hospital-based ${ }^{23}$. The number of baseline participants ranged from 189 to 7,747 individuals (median of 2,000). The mean age at the last follow-up ranged from 2 to 30 years (median of 9 years) and the number of follow-ups ranged from 2 to 11 (median of 4), as observed in Table 1. Sample loss in the last follow-up of the cohorts ranged from 9.2 to $87.5 \%$ (median of $42.0 \%$ ), and the main difficulties reported by the authors were the not knowing the whereabouts of the participants, loss of telephone contact and change of address.

Regarding the explored variables, all cohorts presented contextual measures (socioeconomic, environmental and domestic variables) in at least one of the follow-ups. The most frequent information collected in the perinatal period were characteristics of the moment of delivery, of the newborn, morbidity and life habits of the pregnant woman, while the least frequent was the mental health of the mother. The most investigated characteristics of the participant in childhood were morbidity, dietary practices and breastfeeding, and the least frequent was vaccination. The cohorts that followed up with the participants at school age collected more frequently morbidity data and less frequently, information on oral health. Five cohorts followed participants in adolescence ${ }^{21,23,25,26,29}$ and investigated more frequently morbidity and lifestyle data. Six cohorts followed participants in the early adulthood ${ }^{17,18,21,22,25,26}$, with 


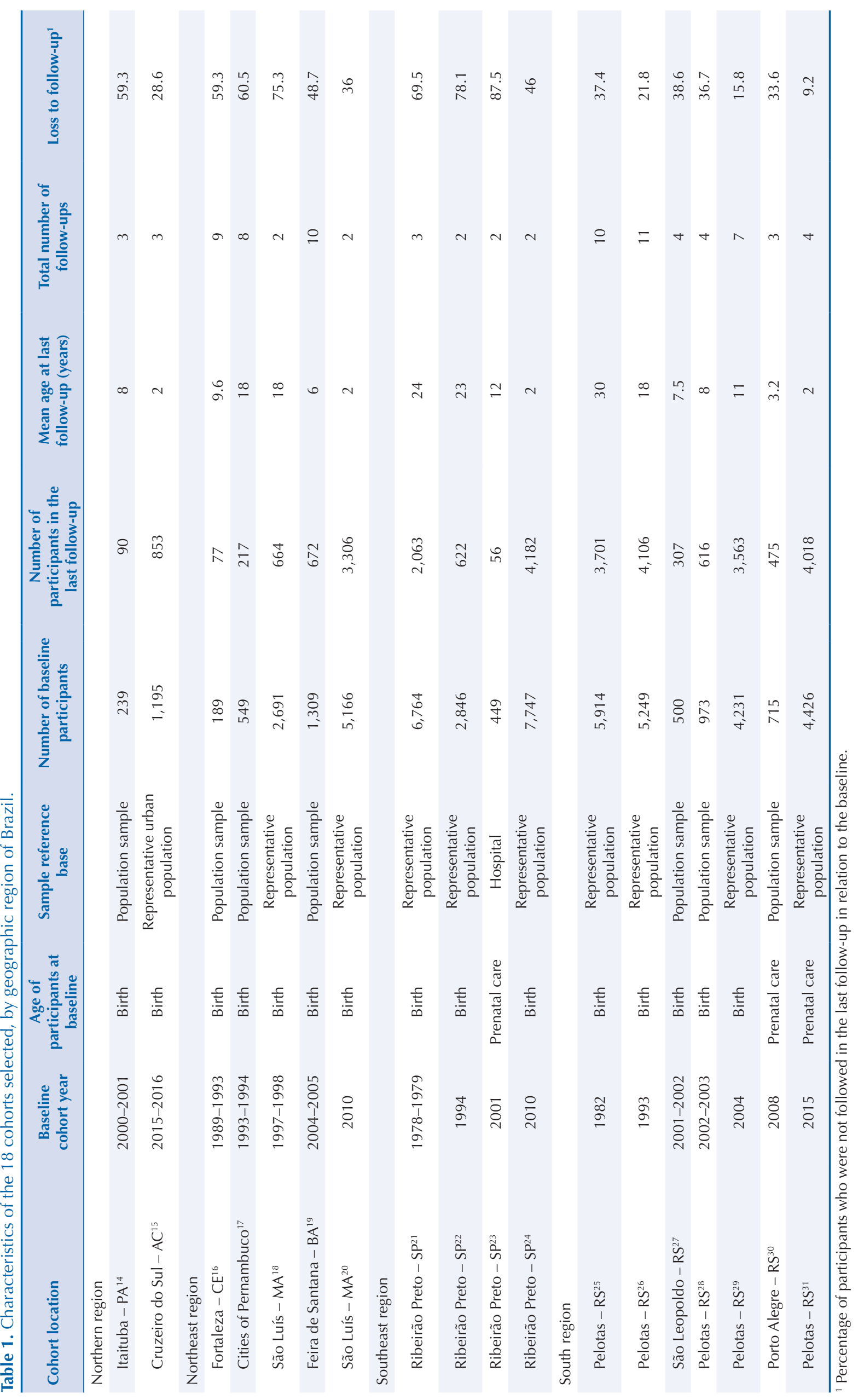


data collection of morbidity, dietary practices, anthropometric measurements, cognition, lifestyle and human capital. The information collected less frequently in adulthood was mental health. Of the total cohorts, 14 collected biological material (blood and/or feces) $)^{14-18,20-22,24-27,29,31}$ at some point in the life cycle (Figure 2).

Figure 3 shows the geographical distribution of cohorts in Brazil. The Northern region included two cohorts. The first began in 2000 in the municipality of Itaituba, in the state of Pará ${ }^{14}$; it included 239 children born between 2000-2001 and carried through three additional follow-ups (at ages four, six, and between eight and ten) for mercury exposure analysis. Loss at the last follow-up regarding this cohort was $59.3 \%$ in relation to the number of baseline participants. The most recent cohort of the Northern region was conducted in the state of Acre, known as the Maternal-Infant study in Acre (Mina), which began between July 2015 and June 2016 in the municipality of Cruzeiro do Sul ${ }^{15}$. The Mina cohort consisted of all live birth infants living in the urban area of the municipality $(n=1,195)$, of which 588 had data collected in the prenatal period (up to the second trimester of pregnancy). This cohort performed three follow-ups with the children so far (at 6, 12 and 24 months) and the loss of follow-up at 24 months was $28.6 \%$.

In the Northeastern region, five cohorts were identified. The cohort of Fortaleza, in Ceará, began in 1989 and included 189 children born in the favela of Gonçalves Dias ${ }^{16}$. These children were monitored every three months during their first two years, in the period between 1989 and 1993, for records of diarrheal diseases, dietary information and anthropometric measurements. This cohort performed a total of nine follow-ups (at 3, 6, 9, 12, 15, 18, 21 and 24 months and between 6 and 12 years of age), with loss at the last follow-up of 59.3\%. The cohort conducted in five municipalities of Pernambuco (Água Preta, Catende, Joaquim Nabuco, Palmares and Ribeirão), started in 1993, included 549 live birth infants between January 1993 and August 199417. This cohort performed eight follow-ups (at 2, 4, 6, 9, 12 and 24 months, at 8 and 18 years) and had a loss in the last follow-up of $60.5 \%$ of the participants. Two population-based cohorts were identified in the city of São Luís, Maranhão. The first, started in 1997, included 2,691 single live birth infants and carried through two follow-ups with participants (between 7 and 9 years and between 18 and 19 years), with loss in follow-up between 18 and 19 years of age of $75.3 \%^{18}$. The second cohort was initiated in 2010, known as Brisa São Luís, and included 5,166 live birth infants at baseline, of which 1,447 had data collected in prenatal care ${ }^{20}$. To date, Brisa São Luís has monitored children between 13 and 30 months, with $36 \%$ of losses compared to baseline. In Bahia, there is a cohort in the municipality of Feira de Santana since April $2004^{19}$; it included 1,309 live birth infants, performed ten follow-ups with the participants (at 1, 2, 3, 4, 5, 6, 9 and 12 months, at 3 years and 6 years) and had a loss of $48.7 \%$ in the last follow-up.

In the Southeast region, four cohorts were identified, all in the city of Ribeirão Preto, in the state of São Paulo. Three were population-based, started in $1978^{21}, 1994^{22}$ and $2010^{24}$, and one was hospital-based, started in $2001^{23}$. The Ribeirão Preto cohort started in 1978 included 6,764 single live birth infants, performed three follow-ups (between 8 and 11 years old, at age 18 - only for male participants - and between ages 23 and 25) and had $69.5 \%$ of loss in the last follow-up. The one started in 1994 included 2,846 single live birth infants and carried through two follow-ups with participants (between 9 and 11 years and between 22 and 24 years), with loss in follow-up between 78,1 and 19 years of age of $75.3 \%$. The cohort started in 2010, known as Brisa Ribeirão Preto, included 2,443 single live birth infants of that year, of which 1,417 had data collected in the prenatal period. To date, it has monitored children between 13 and 30 months of life, with loss of follow-up of 46\%. The Ribeirão Preto cohort started in 2001, known as the Gesta-Álcool Project, monitored 449 pregnant women in the third trimester of pregnancy and conducted two follow-ups with the participants (between 6 and 7 years and between 11 and 12 years), with a loss of $87.5 \%$ in the last follow-up.

In the Southern region of the country, seven cohorts were identified, all in the state of Rio Grande do Sul. We highlight the population-based cohorts of Pelotas, given the high number 


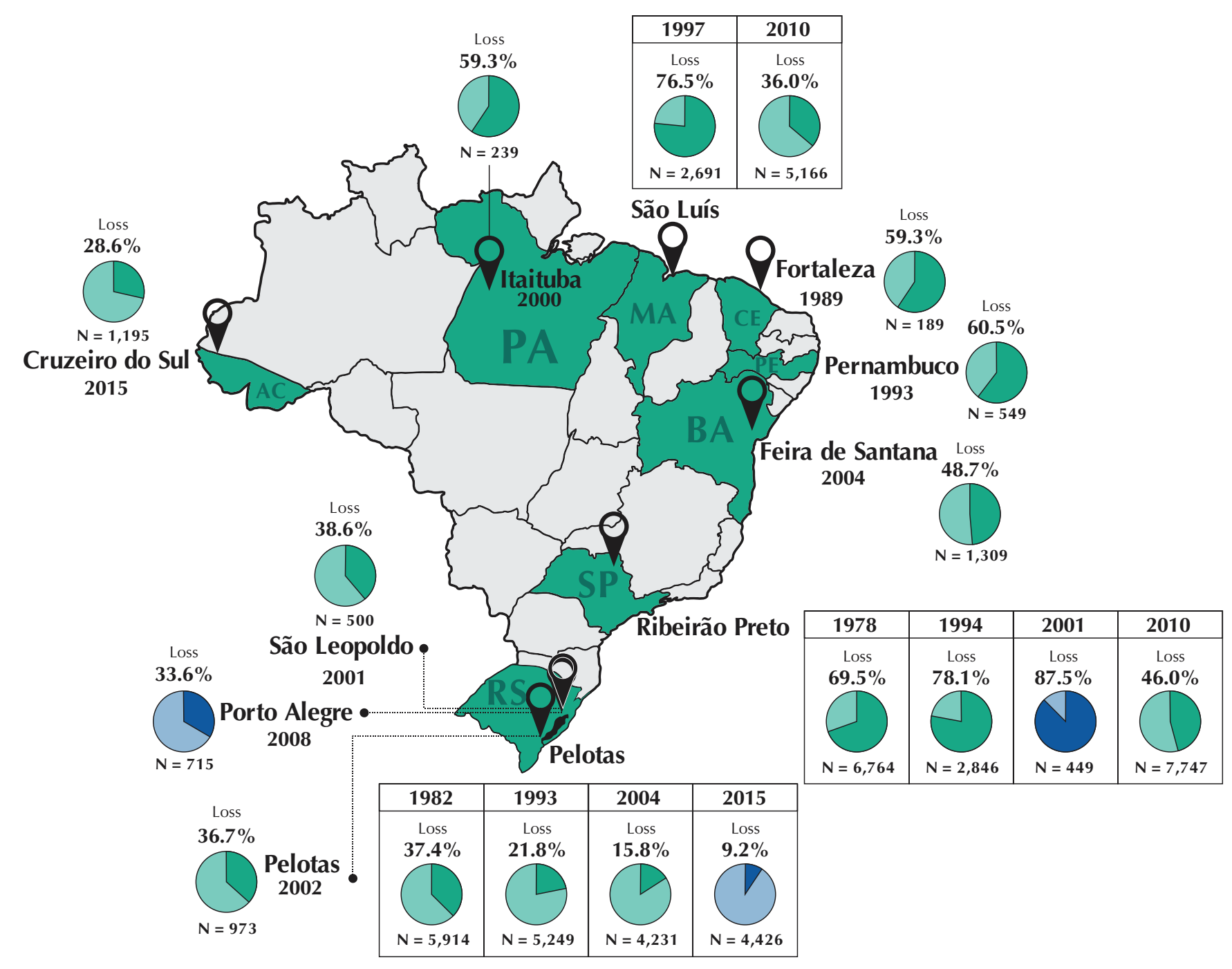

At birth

Prenatal care

Figure 3. Map of Brazil with geographical distribution of the selected cohorts.

of individuals recruited, the greater number of follow-ups with the participants and for having followed their participants from birth to adolescence and early adult life. Of the 345 articles selected in this systematic review, $75 \%$ corresponded to publications derived from these cohorts. The first cohort of Pelotas was initiated in 1982 and involved 5,914 children, with nine follow-ups to date (at ages 1, 2, 4, 13, 15, 18, 19, 23 and 30) ${ }^{25}$. Subsequent and still ongoing cohorts involved 5,249 births in 1993 with 11 follow-ups (at 1, 3 and 6 months, 1, 4, $6,9,11,12$ to 13,15 and 18 years) ${ }^{26} ; 4,231$ births in 2004 with seven follow-ups (at 3 months, $1,2,4,5,7$ and 11 years $)^{29}$ and, in the most recent cohort, 4,226 prenatal recruitments in 2015 with four follow-ups to date (at birth, 3 months, 1 and 2 years). The losses in the last follow-up of the Pelotas cohorts of 1982, 1993, 2004 and 2015 were, respectively, 37.4\%, $21.8 \%, 15.8 \%$ and $9.2 \%$. The other three cohorts identified were the one in São Leopoldo, started in $2001^{27}$, in Pelotas started in $2002^{28}$ and in Porto Alegre started in $2008^{30}$. The São Leopoldo cohort recruited 500 mother-child pairs between October 2001 and June 2002 and carried out four follow-ups with the participants (at 6 months, 12 months, 4 years and 7 to 8 years), with loss at the last follow-up of $38.6 \%$. The Pelotas cohort included all 2,741 live birth infants between September 2002 and May 2003 in the urban area of the municipality and followed a random sample of $30 \%(n=973)$ at 1,3 and 6 months of life and at 8 years of age, with a loss of $36.7 \%$ at the last follow-up. The Porto Alegre cohort started with 715 pregnant women recruited in the third week of pregnancy and performed three follow-ups (from 6 to 9 months, 12 to 16 months and 2 to 3 years), with $33.6 \%$ loss at the last follow-up. 


\section{DISCUSSION}

The Brazilian cohorts identified, initiated in the prenatal or birth period, were prospective and collected primary data. To date, few have followed participants in adolescence $(n=6)$ and adulthood $(\mathrm{n}=5)$. Six cohorts stood out by the largest number of baseline participants, the comprehensive approach to the health of children, adolescents and adults and by accompanying participants in more phases of the life cycle: the Pelotas birth cohorts of $1982^{25}, 1993^{26}$ and $2004^{29}$, the Ribeirão Preto cohorts of $1978^{21}$ and $1994^{22}$ and the São Luís cohort of $1997^{18}$. The losses of follow-up were related to not knowing the whereabouts of the participants, to internal migration and refusals to further participation. The most explored variables were related to sociodemographic, environmental and domestic family data, maternal morbidity and lifestyle, additional morbidity data, breastfeeding and nutritional practices during infancy, morbidity during school age, morbidity and lifestyle during adolescence and aspects of integral health during adulthood.

In high-income countries, prenatal and birth cohorts, in addition to accompanying their participants for a prolonged time, are not limited to single-generation individuals; it also includes their descendant ${ }^{32,33}$, allowing for intergenerational analyses. On the other hand, the prenatal and birth cohorts of middle and low-income countries frequently present difficulties related to lack of financial resources, early death of children and internal migration, and infrequent follow-up of participants in more advanced stages of the life cycle ${ }^{12}$.

Some methodological characteristics and difficulties of the identified cohorts were observed. Most monitored two phases of the life cycle (perinatal period and childhood). Although there is a requirement for immediate results to satisfy and stimulate the funders and participants of the study, it is known that the most important results from the perspective of the life cycle are those that analyze the influence of early exposures on health and well-being in later stages of life and with repeated measures at different stages of an individual's life ${ }^{34}$. Sample size and follow-up losses were weak points of most identified cohorts. Reducing the loss of follow-up over time represents a challenge, since differential losses between exposed and unexposed groups tend to introduce biases in cohort studies ${ }^{5,6}$.

The development process of cohort studies is challenging. The implementation of a cohort requires close collaboration between the institutions involved, health professionals and families, as well as laborious logistics for the correct execution of the phases of the study (preparation of data collection instruments, recruitment and training of study personnel, pilot phase, monitoring of participants), including quality control procedures in all stages $^{35,36}$. In addition to this investment of time, effort and intellectual contribution, keeping a cohort study running is quite costly. The adequacy of funding might determine the timespan of the study. Cohort studies are often funded by government agencies and international organizations, and therefore are vulnerable to political and governmental priorities, or by local research foundations that do not guarantee the sustainability and availability of long-term financial resources ${ }^{37}$.

The development of cohorts in Brazil is important for several reasons. New exposures resulting from demographic, epidemiological, nutritional and institutional transitions in the country create a demand for new investigations on its effects on the health of the Brazilian population..$^{38}$ The possibility of verifying the nature of the associations between exposures and outcomes in different contexts and comparing results between existing cohorts is another advantage ${ }^{13,39,40}$. Brazilian cohorts have the potential to further contribute the scientific capacity of the country, with the training of researchers and improvement of the process of collecting and analyzing data ${ }^{11}$, in addition to assisting decision makers in the analysis of health determinants and in strengthening the health care provided ${ }^{41}$.

In view of the importance of cohorts initiated in the prenatal period and at birth in Brazil, the dichotomy between the development of new cohorts or investment in existing cohorts 
is discussed. International authors advocate the establishment of new population-based cohorts in countries with socioeconomic and racial/ethnic diversity, with annual follow-ups and evaluation of exposures of greater local relevance for multiple health outcomes? ${ }^{7}$ This argument is justified by providing opportunities for collection of new risk information and recruiting underrepresented participants in existing studies, but faces serious budgetary challenges required by cohorts of this size ${ }^{42}$. On the other hand, other authors ${ }^{43,44}$ argue that representativeness is not necessary to determine the relationship between environmental or genetic factors and the risk of disease. These scholars suggest strategies for combining data from existing cohorts ${ }^{44}$ and with the formation of national and international cohort consortia ${ }^{43}$. A systematic review study of European cohorts concluded that a network of coordinated cohort studies, following a harmonized general protocol with a perspective of joint interpretation of data, would increase the scientific impact and international collaboration interest in these researches ${ }^{45}$.

The cohorts with a representative population of Pelotas, Ribeirão Preto and São Luís correspond to the birth cohorts with the greatest potential to study biological, behavioral, social and genetic precursors of chronic diseases in Brazil. The ones in Pelotas are the largest population-based birth cohort studies in low- and middle-income countries with nearly four decades of work, more than 20,000 individuals studied throughout life, regular assessments in childhood and adolescence, and smaller rates of loss at follow-up. The birth cohorts of Ribeirão Preto and São Luís, initiated in partnership with the same group of researchers, studied about 17,000 and 7,000 individuals, respectively, and foresee more follow-ups with their participants. Located in a region with distinct sociocultural characteristics and lacking research, the Mina cohort, in Cruzeiro do Sul, Acre, also has the potential to contribute to life cycle studies in Brazil, since it is the first cohort initiated in with an integral approach to children's health in the Amazon region.

In conclusion, this review identified cohorts initiated in the prenatal period and at birth in Brazil with potential for life course epidemiology studies. These cohorts differ in sample size, number of follow-ups and phase of the life cycle in which individuals were monitored, as well as rates of loss of follow-up. It is recommended that the Brazilian cohorts initiated in the prenatal period and at birth have enough participants to perform analyses of the effect of early determinants on health outcomes in the short, medium and long term. In addition, in order to expand the epidemiology analyses of the life course in Brazil, it is necessary that the existing cohorts contemplate different social contexts and follow-ups with the participants at different stages of life.

\section{REFERENCES}

1. Kuh D, Bem-Shlomo Y, Susser E, editors. A life course approach to chronic disease epidemiology. New York: Oxford University Press; 2004.

2. Ben-Shlomo Y, Kuh D. A life course approach to chronic disease epidemiology: conceptual models, empirical challenges and interdisciplinary perspectives. Int J Epidemiol. 2002;31(2):285-93. https://doi.org/10.1093/ije/31.2.285

3. Kuh D, Ben-Shlomo Y, Lynch J, Hallqvist J, Power C. Life course epidemiology. J Epidemiol Community Health. 2003;57(10):778-83. https://doi.org/10.1136/jech.57.10.778

4. Buka SL, Rosenthal SR, Lacy ME. Epidemiological study designs: traditional and novel approaches to advance life course health development research. In: Halfon N, Forreest CB, Lerner RM, editors. Handbook of life course health development. New York: Springer; 2018. p. 541-60.

5. Grimes DA, Schulz KF. Cohort studies: marching towards outcomes. Lancet. 2002;359(9303):341-5. https://doi.org/10.1016/S0140-6736(02)07500-1

6. Mann C. Observational research methods. Research design II: cohort, cross sectional, and case-control studies. Emerg Med J. 2003;20(1):54-60. https://doi.org/10.1136/emj.20.1.54 
7. Manolio TA, Bailey-Wilson JE, Collins FS. Genes, environment and the value of prospective cohort studies. Nat Rev Genet. 2006;7(10):812-20. https://doi.org/10.1038_nrg1919

8. Susser E, Terry MB, Matte T. The birth cohorts grow up: new opportunities for epidemiology. Paediatr Perinat Epidemiol. 2000;14(2):98-100. https://doi.org/10.1046/j.1365-3016.2000.00249.x

9. Power C, Kuh D, Morton S. From developmental origins of adult disease to life course research on adult disease and aging: insights from birth cohort studies. Annu Rev Public Health. 2013;34:7-28. https://doi.org/10.1146/annurev-publhealth-031912-114423

10. Araujo WRM, Santos IS, Barros FC, Matijasevich A. Birth cohort studies and the early origins of adult health and disease. Neoreviews. 2018;19(6):e313-21. https://doi.org/10.1542/neo.19-6-e313

11. Batty G, Alves JG, Correia J, Lawlor DA. Examining life-course influences on chronic disease: the importance of birth cohort studies from low-and middleincome countries: an overview. Braz J Med Biol Res. 2007;40(9):1277-86. https://doi.org/10.1590/S0100-879X2007000900015

12. Arksey H, O'Malley L. Scoping studies: towards a methodological framework. Int J Soc Res Methodol. 2005;8(1):19-32. https://doi.org/10.1080/1364557032000119616

13. Barreto ML; Almeida Filho N. Abordagens epidemiológicas do curso de vida. In: Almeida Filho N; Barreto ML. Epidemiologia \& saúde: fundamentos, métodos, aplicações. Rio de Janeiro: Guanabara Koogan; 2011. p.399

14. Dutra MDS, Jesus IM, Santos ECO, Lima MO, Medeiros RLFM, Cavadas M, et al. Longitudinal assessment of mercury exposure in schoolchildren in an urban area of the Brazilian Amazon. Cad Saude Publica. 2012;28(8):1539-45. https://doi.org/10.1590/S0102-311X2012000800012

15. Neves PAR, Castro MC, Oliveira CVR, Malta MB, Lourenço BH, Cardoso MA; MINA-Brazil Study Group. Effect of Vitamin A status during pregnancy on maternal anemia and newborn birth weight: results from a cohort study in the Western Brazilian Amazon. Eur J Nutr. 2018;1-12. https://doi.org/10.1007/s00394-018-1880-1

16. Lorntz B, Soares AM, Moore SR, Pinkerton R, Gansneder B, Bovbjerg VE, et al. Early childhood diarrhea predicts impaired school performance. Pediatr Infect Dis J. 2006;25(6):513-20. https://doi.org/10.1097/01.inf.0000219524.64448.90

17. Goncalves FCLSP, Amorim RJM, Eickmann SH, Lira PCI, Lima MC. The influence of low birth weight body proportionality and postnatal weight gain on anthropometric measures of 8-year-old children: a cohort study in Northeast Brazil. Eur J Clin Nutr. 2014;68(8):876-81. https://doi.org/10.1038/ejcn.2014.68

18. Silva AAM, Batista RFL, Simões VMF, Thomaz EBAF, Ribeiro CCC, Lamy Filho F, et al. Changes in perinatal health in two birth cohorts (1997/1998 and 2010) in São Luís, Maranhão State, Brazil. Cad Saude Publica. 2015;31(7):1437-50. https://doi.org/10.1590/0102-311X00100314

19. Brandão HV, Vieira GO, Vieira TO, Cruz AA, Guimarães AC, Teles C, et al. Acute viral bronchiolitis and risk of asthma in schoolchildren: analysis of a Brazilian newborn cohort. J Pediatr (Rio J). 2017;93(3):223-9. https://doi.org/10.1016/j.jped.2016.08.004

20. Silva FS, Barbosa YC, Batalha MA, Ribeiro MRC, Simões VMF, Branco MRFC, et al. Incompletude vacinal infantil de vacinas novas e antigas e fatores associados: coorte de nascimento BRISA, São Luís, Maranhão, Nordeste do Brasil. Cad Saude Publica. 2018;34(3):e00041717. https://doi.org/10.1590/0102-311X00041717

21. Cardoso VC, Meritano J, Silva AAM, Bettiol H, Barbieri MA, Grandi C. Size at birth and blood pressure in young adults: findings from a Brazilian birth cohort study. Rev Saude Publica. 2012;46(6):978-87. https://doi.org/10.1590/S0034-89102013005000009

22. Saur AM, Loureiro SR. Mental health of small children for normal gestational age: a cohort study from Southeastern Brazil. Psicol Reflex Crit. 2015;28(1):204-12. https://doi.org/10.1590/1678-7153.201528122

23. Furtado EF, Roriz STS. Inattention and impulsivity associated with prenatal alcohol exposure in a prospective cohort study with 11-years-old Brazilian children. Eur Child Adolesc Psychiatry. 2016;25(12):1327-35. https://doi.org/10.1007/s00787-016-0857-y

24. Sbrana M, Grandi C, Brazan M, Junquera N, Nascimento MS, Barbieri MA, et al. Alcohol consumption during pregnancy and perinatal results: a cohort study. Sao Paulo Med J. 2016;134(2):146-52. https://doi.org/10.1590/1516-3180.2015.02040211 
25. Horta BL, Gigante DP, Gonçalves H, Motta JVS, Loret de Mola C, Oliveira IO, et al. Cohort profile update: the 1982 Pelotas (Brazil) Birth Cohort Study. Int J Epidemiol. 2015;44(2):441-441e. https://doi.org/10.1093/ije/dyv017

26. Victora CG, Hallal PC, Araujo CLP, Menezes AMB, Wells JCK, Barros FC. Cohort profile: the 1993 Pelotas (Brazil) Birth Cohort Study. Int J Epidemiol. 2008;37(4):704-9. https://doi.org/10.1093/ije/dym177

27. Rauber F, Campagnolo PDB, Hoffman DJ, Vitolo MR. Consumption of ultra-processed food products and its effects on children's lipid profiles: a longitudinal study. Nutr Metab Cardiovasc Dis. 2015;25(1):116-22. https://doi.org/10.1016/j.numecd.2014.08.001

28. Dutra GF, Kaufmann CC, Pretto AD, Albernaz EP. Sedentary lifestyle and poor eating habits in childhood:a cohort study. Cienc Saude Coletiva. 2016;21(4):1051-9. https://doi.org/10.1590/1413-81232015214.08032015

29. Santos IS, Barros AJD, Matijasevich A, Zanini R, Cesar MAC, Camargo-Figuera FA, et al. Cohort profile update: 2004 Pelotas (Brazil) Birth Cohort Study. Body composition, mental health and genetic assessment at the 6 years follow-up. Int J Epidemiol. 2014;43(5):1437a-f. https://doi.org/10.1093/ije/dyu144

30. Zandona MR, Sangalli CN, Campagnolo PDB, Vitolo MR, Almeida S, Mattevi VS. Validation of obesity susceptibility loci identified by genome-wide association studies in early childhood in South Brazilian children. Pediatr Obes. 2017;12(1):85-92. https://doi.org/10.1111/ijpo.12113

31. Hallal PC, Bertoldi AD, Domingues MR, Silveira MF, Demarco FF, Silva ICM, et al. Cohort profile: the 2015 Pelotas (Brazil) Birth Cohort Study. Int J Epidemiol. 2018;47(4);1048-1048h. https://doi.org/10.1093/ije/dyx219

32. Elliott J, Shepherd P. Cohort profile: 1970 British Birth Cohort (BCS70). Int J Epidemiol. 2006;35(4):836-43. https://doi.org/10.1093/ije/dyl174

33. Boyd A, Golding J, Macleod J, Lawlor DA, Fraser A, Henderson J, et al. Cohort profile: the 'Children of the 90s': the index offspring of the Avon Longitudinal Study of Parents and Children. Int J Epidemiol. 2013;42(1):111-27. https://doi.org/10.1093/ije/dys064

34. Golding J. Who should be studied and when in a longitudinal birth cohort? Paediatr Perinat Epidemiol. 2009;23 Suppl 1:15-22. https://doi.org/10.1111/j.1365-3016.2008.00998.x

35. Golding J. Preparation, piloting and validation for a longitudinal birth cohort study. Paediatr Perinat Epidemiol. 2009;23 Suppl 1:201-12. https://doi.org/10.1111/j.1365-3016.2009.01017.x

36. Silveira MF, Barros FC, Sclowitz IKT, Domingues MR, Mota DM, Fonseca SS, et al. Implementation of the INTERGROWTH 21st Project in Brazil. BJOG. 2013;120 Suppl 2:81-6. https://doi.org/10.1111/1471-0528.12046

37. Doyle A, Golding J. The costing and funding of longitudinal birth cohort studies. Paediatr Perinat Epidemiol. 2009;23 Suppl 1:86-92. https://doi.org/10.1111/j.1365-3016.2008.01011.x

38. Mendes ACG, Sá DA, Miranda GMD, Lyra TM, Tavares RAW. Assistência pública de saúde no contexto da transição demográfica brasileira: exigências atuais e futuras. Cad Saude Publica. 2012;28(5):955-64. https://doi.org/10.1590/S0102-311X2012000500014

39. Brion M-JA, Lawlor DA, Matijasevich A, Horta B, Anselmi L, Araújo CL, et al. What are the causal effects of breastfeeding on IQ, obesity and blood pressure? Evidence from comparing high-income with middle-income cohorts. Int J Epidemiol. 2011;40(3):670-80. https://doi.org/10.1093/ije/dyr020

40. Lawlor DA, Andersen AMN, Batty GD. Birth cohort studies: past, present and future. Int J Epidemiol. 2009;38(4):897-902. https://doi.org/10.1093/ije/dyp240

41. Santos IS, Barros AJ, Matijasevich A, Domingues MR, Barros FC, Victora CG. Cohort profile: the 2004 Pelotas (Brazil) Birth Cohort Study. Int J Epidemiol. 2011;40(6):1461-8. https://doi.org/10.1093/ije/dyq130

42. Collins FS, Manolio TA. Merging and emerging cohorts: necessary but not sufficient. Nature. 2007;445(7125):259. https://doi.org/10.1038/445259a

43. Kishi R, Araki A, Minatoya M, Itoh S, Goudarzi H, Miyashita C. Birth cohorts in Asia: the importance, advantages, and disadvantages of different-sized cohorts. Sci Total Environ. 2018;615:1143-54. https://doi.org/10.1016/j.scitotenv.2017.08.268 
44. Willett WC, Blot WJ, Colditz GA, Folsom AR, Henderson BE, Stampfer MJ. Merging and emerging cohorts: not worth the wait. Nature. 2007;445(7125):257-8. https://doi.org/10.1038/445257a

45. Piler P, Kandrnal V, Bláha L. Critical assessment of the research outcomes of European birth cohorts: linking environmental factors with non-communicable diseases. Public Health. 2017;145:136-45. https://doi.org/10.1016/j.puhe.2016.12.037

Funding: WRMA received support from Coordenação de Aperfeiçoamento de Pessoal de Nivel Superior (CAPES) through a doctorate scholarship (Process 001/2017).

Authors' contribution: Study design: WRMA, AM. Data collection and interpretation: WRMA, AM. Elaboration and review of the manuscript: ISS, NAQM, MTCCdS and AJLAdC. Approval of the final version and public responsibility for the article: all authors.

Conflict of interest: The authors declare no conflict of interest. 